\title{
The predictive value of baseline volumetric PET/CT parameters on treatment response and prognosis in locally-advanced rectal cancer treated with neoadjuvant chemoradiotherapy
}

Abdullah SAKiN ( $\square$ drsakin@hotmail.com)

Yuzuncu Yil University: Van Yuzuncu Yil Universitesi https://orcid.org/0000-0003-2538-8569

\section{Suleyman Sahin}

Van Egitim ve Arastirma Hastanesi

\section{Sevda Saglampınar Karyagar}

Okmeydani Egitim ve Arastirma Hastanesi: Turkiye Cumhuriyeti Saglik Bakanligi Okmeydani Egitim ve Arastirma Hastanesi

\section{Savas Karyagar}

Okmeydani Egitim ve Arastirma Hastanesi: Turkiye Cumhuriyeti Saglik Bakanligi Okmeydani Egitim ve Arastirma Hastanesi

\section{Muhammed Mustafa atci}

Okmeydani Egitim ve Arastirma Hastanesi: Turkiye Cumhuriyeti Saglik Bakanligi Okmeydani Egitim ve Arastirma Hastanesi

\section{Mustafa Halil Akboru}

Okmeydani Egitim ve Arastirma Hastanesi: Turkiye Cumhuriyeti Saglik Bakanligi Okmeydani Egitim ve Arastirma Hastanesi

\section{Sener Cihan}

Okmeydani Egitim ve Arastirma Hastanesi: Turkiye Cumhuriyeti Saglik Bakanligi Okmeydani Egitim ve Arastirma Hastanesi

\section{Research Article}

Keywords: Rectal cancer, metabolic tumor volume, tumour lesion glycolysis, neoadjuvant chemoradiotherapy, $\mathrm{PET} / \mathrm{CT}$, volumetric parameters

Posted Date: February 11th, 2021

DOl: https://doi.org/10.21203/rs.3.rs-212603/v1

License: (c) (i) This work is licensed under a Creative Commons Attribution 4.0 International License. Read Full License 
Version of Record: A version of this preprint was published at Journal of Gastrointestinal Cancer on March 2nd, 2021. See the published version at https://doi.org/10.1007/s12029-021-00608-y. 


\section{Abstract}

Purpose:To investigate the prognostic effects of baseline volumetric PET/CT parameters including the maximum standard uptake value(SUVmax), metabolic tumor volume(MTV), and tumor lesion glycolysis(TLG) on treatment response and prognosis in locally-advanced rectal cancer(LARC) treated with neoadjuvant chemoradiotherapy(NACRT).

Methods:Between 2015 and 2018, 51 patients with LARC treated with NACRT followed by surgery were included in this retrospective study. Patients were divided into 2 groups by tumor regression grade(TRG) as follows;Group I=TRG 1(No detectable cancer cells)+TRG 2(single cells and/or small groups of cancer cells) and Group II=TRG3(residual tumor outgrown by fibrosis)+TRG 4(remarkable fibrosis outgrown by tumor cells)+TRG 5(No fibrosis with extensive residual cancer).

Results:Of the 51 patients, 34(66.7\%) were male. The median age was 55(range,37-78) years. According to TRG status, $14(27.4 \%)$ patients were in group I and $37(72.6 \%)$ patients were in group II. The area under the curve $(95 \% \mathrm{Cl})$ was $0.749(0.593-0.905)$ in the ROC curve plotted for MTV. The cut of value for MTV was 12 , with $70 \%$ sensitivity and $65 \%$ specificity. MTV was $\geq 12$ in $32(62.8 \%)$ patients. MTV and TLG values were significantly different between Group I and II, whereas there was no significant difference between the groups in terms of SUVmax values $(p=0.006, p=0.033$, and $p=0.673$, respectively). The disease-free survival was not reached in patients with MTV $<12$ vs. 20 months in those with MTV $\geq 12$ $(p=0.323)$. In multivariate analysis, MTV(OR, 95\% Cl, 5.00[1.17-21.383]) was found to be the factor that affected pathological complete response.

Conclusion:In LARC treated with NACRT, MTV prior to treatment can help predict the response to treatment.

\section{Introduction}

Locally-advanced rectal cancer (LARC) refers to as rectal cancer that invades through the muscularis propria into pericolorectal tissue as well as invading regional lymph nodes in the absence of distant metastatis[1]. Currently, total mesorectal excision following neoadjuvant chemoradiotherapy (NACRT) is the mainstay of treatment for LARC[2,3].

There is no standard method to predict the pathological tumor response after NACRT in LARC patients. Numerous studies have shown that pathological complete response (pCR) increases survival rates [4-8]; however, only $15-25 \%$ of rectal cancer patients can achieve PCR $[9,10]$. Therefore, the question of surgical necessity has been raised for this group of patients[11]. In studies, the 'watch-and-wait' approach is considered as an alternative to surgery, with better functional outcomes and similar disease-free survival (DFS) and overall survival rates as well as providing organ preservation[12, 13]. In addition, NACRT in lowrisk tumors may increase the chance of 'observation without surgery approach' instead of undergoing rectal surgery[14]. 
Today, positron emission tomography with 2-deoxy-2- [fluorine-18] Flu-D-glucose integrated with computed tomography (18F-FDG-PET/CT) is a useful imaging method in oncological practice. FDG is a glucose analogue which gathers in metabolically-active tumor cells[15]. The metabolic tumour volume (MTV) represents the volume of interest with abnormal FDG accumulation which is reproduced from two methods as follows; utilizing a fixed standardized uptake value (SUV) cut-off of 2.5 and a threshold of $42 \%$ of SUVmax. The tumour lesion glycolysis (TLG) indicates the volume and density of an FDG avid area calculated by the following formula; TLG = SUVmean $\times$ MTV. The changes between serial scans were measured as absolute and percentage changes[16].

In previous studies, the prognostic effect of MTV has been demonstrated in many solid tumors such as non-small cell lung cancer, breast cancer, stomach cancer, endometrial cancer and anal cancer as well as rectum cancer [12,17-22]. In this study, we aimed to investigate the effect of volumetric 18F-FDG-PET/CT parameters (SUVmax, MTV, and TLG) on tumor regression grade (TRG) response in LARC treated with NACRT.

\section{Methods}

\section{Patient characteristics}

A total of 51 patients with LARC who were followed up and treated at oncology department between 2015 and 2018 were analyzed retrospectively. Inclusion criteria were defined as follows; age $\geq 18$ years, clinical stage III disease, and patients treated with surgery following NACRT with capecitabine who underwent baseline and post-treatment 18C-FDG-PET/CT imaging. Patients younger than 18 years of age, multiple primary tumors, metastatic disease at diagnosis, and those who could not tolerate NACRT, and patients with missing data were excluded from the study.

\section{Data Collection}

Clinical and demographic data including age, gender, cigarette smoking, alcohol consumption, presence of comorbid disease (e.g., diabetes mellitus, hypertension), Eastern cooperative group performance score (ECOG PS), tumor grade, post-operative pathological stage (ypTNM), presence of perineural invasion (PNI) or lymphovascular invasion ( $\mathrm{LVI}$ ), response to NACRT, adjuvant therapy, recurrence, and final (exitus vs. alive) status were obtained from archive files or hospital medical records. Patients were restaged according to the tumor-node metastasis (TNM) classification by the American Joint Committee on Cancer (AJCC)/Union for International Cancer Control (UICC) staging system, 8th edition, 2017. After NACRT, patients were divided into 2 groups based on the Ryan TRG[23] as follows; Group1=TRG 1 (No viable cancer cells) + TRG 2 (Single cells or small groups of cancer cells), Group 2= TRG3 (Residual cancer outgrown by fibrosis) + TRG 4 (Significant fibrosis outgrown by cancer) + TRG 5 (No fibrosis with extensive residual cancer)

Neoadjuvant Chemoradiotherapy 
All patients received concurrent radiotherapy (45-50 Gy in 25-28 fractions to pelvic lymph nodes and mesorectum) and capecitabine ( $825 \mathrm{mg} / \mathrm{m} 2$ PO BID on days 1-5 for 5 weeks). About 8-10 weeks after neoadjuvant treatment, patients underwent surgery of total mesocolon excision and lymph node dissection.

\section{FDG-PET imaging protocol}

Whole-body 18F-FDG-PET/CT scans were carried out through LSO-based full ring PET scanner (Siemens Biograph 6, Chicago, IL, USA). Following a 6-hour of fasting period, $370-555 \mathrm{MBq} 18 \mathrm{~F}-\mathrm{FDG}$ was injected. About 1 hour was allowed for the distribution of 18F-FDG. Whole-body computed tomography (CT) scans were attained (skull base to mid-thigh), with a slice collimation of $5 \mathrm{~mm}$ and a slice interval of $3.4 \mathrm{~mm}$. The emission data were acquired for $2.5 \mathrm{~min}$ per bed (6-7 beds), which were later attenuation corrected with the digital CT data. Image reconstruction used ordered subsets expectation maximization algorithm of 2 iterations and 8 subsets. Image analysis was performed on the Esoft multimodality computer platform (Siemens Medical Solutions, Erlangen, Germany).

\section{FDG-PET analysis}

Two nuclear physician experts interpreted the images. If a relative FDG accumulation was observed to increase compared to normal surrounding tissues, the FDG uptake was then identified as a representing a tumor. The SUVmax of the primary tumor, lymph nodes and SUVmean, MTV $\left(\mathrm{cm}^{3}\right)$ of primary tumor were produced automatically from the volume of interest by the work station. The margin of the target lesion inside the VOI was automatically produced and voxels greater than a threshold of $41 \%$ of SUVmax in the VOI were defined to measure MTV and SUVmean. The TLG was calculated by the MTV multiplying the SUVmean.

\section{Statistical Analysis}

SPSS 22.0 for Windows software was used for the statistical analysis. Descriptive statistics were presented as the mean, standard deviation, minimum, and maximum values for numerical variables; and as number and percentage for categorical variables. Numerical variable between two independent groups were analyzed with student t-test in case of normal distribution and with Mann Whitney $U$ test if else. The comparison of the rates between the groups was performed by chi-square analysis. Monte Carlo simulation was applied if conditions could not be met. Survival analyses were performed with KaplanMeier method. Determinant factors were examined with cox regression analysis. Backward stepwise model was used with parameters having a p-value below 0.250 . An overall $5 \%$ alpha error level was used to infer statistical significance. Cut-off value was determined with receiver operating characteristic curve (ROC) analysis. DFS was calculated as the time from the date of diagnosis until the date of recurrence develops.

\section{Results}


Of the 51 patients, $34(66.7 \%)$ were male and 17 (33.3\%) were female. The mean age was 55 (range, 3778) years. According to TRG groups, 14 (27.4\%) patients were in group I and 37 (72.6\%) patients were in group II. In $5(9.8 \%)$ patients, tumor histology was mucinous adenocarcinoma. According to postoperative pathological staging (ypTNM), 16 (31.4\%) patients were stage $0-1,20$ (39.2\%) patients were stage II, and 15 (29.4\%) patients were stage III. Surgical margin was positive in $3(5.9 \%)$ patients. Adjuvant therapy was given in $41(80.4 \%)$ patients. At a median 11-month follow-up time, 11 (21.6\%) patients had recurrence and $2(3.9 \%)$ patients died (Table 1). There was no significant difference between the TRG groups in terms of clinical and demographic data, except for the ypTNM phase (Table1). Median MTV was 10.4 in Group I and 19.5 in Group II ( $p=0.006)$. The median TLG was 95.2 in Group I and 181.1 in Group II ( $p=0.033)$. Median SUVmax was 9.5 in Group I and 8.8 in Group II ( $p=0.673)$ (Table 2). In the ROC curve plotted for MTV and TLG, the areas under the curve $(95 \% \mathrm{Cl})$ were $0.749(0.593-0.905)$ and $0.695(0.536-0.854)$, respectively. The cut-off value for MTV was 12 , with $70 \%$ sensitivity and $65 \%$ specificity. The cut-off value for TLG was 92.4 , with $75 \%$ sensitivity and $58 \%$ specificity (Figure 1 ).

MTV was < 12 in 19 (37.2\%) patients. The mDFS could not be reached in patients with $M T V<12$, whereas mDFS was 20 months in patients with MTV $\geq 12$ (Log rank $p=0.323$ ) (Figure 2). In multivariate analysis, MTV $<12(\mathrm{OR}, 5.00[95 \% \mathrm{Cl}, 1.17-21.383], \mathrm{p}=0.030)$ was determined as the only factor affecting the TRG (Table 3 ).

\section{Discussion}

In this study, the effects of baseline FDG-PET/CT parameters including SUVmax, MTV, and TLG on TRG were evaluated in LARC patients treated with NACRT followed by surgery. The cut-off value for MTV was 12 , with $70 \%$ sensitivity and $65 \%$ specificity. In the present study, while the SUVmax and TLG did not affect TRG, having a MTV $<12$ prior to treatment increased the response rate by 5 times. In addition, mDFS was 20 months in patients with MTV $\geq 12$, whereas it could not be reached in patients with MTV < 12.

In rectal cancer, standard imaging methods such as magnetic resonance imaging, CT, and endoscopic transrectal ultrasound are very useful for initial diagnosis and staging, but not for predicting the $\mathrm{pCR}$ rates following NACRT[24, 25].

18F-FDG-PET/CT evaluates the metabolic activity of tissue using glucose metabolism and is used to evaluate the response to treatment as well as initial clinical staging. Many previous studies have shown that 18F-FDG-PET/CT can be an indicator of response to treatment in many solid tumors including nonsmall cell lung cancer, breast cancer, and rectum cancer[26-28].

MTV and TLG, which are tumor metabolic activity measurements determined by $18 \mathrm{~F}-\mathrm{FDG}-\mathrm{PET} / \mathrm{CT}$, may have clinical value in terms of response evaluation as well as identifying disease prognosis. In our previous study with breast cancer patients treated with neoadjuvant chemotherapy, we also showed that high MTV decreased treatment response[19]. In a study of anal canal tumors performed by Gauthé et al., it was observed that high MTV prior to treatment significantly reduced survival rates[29]. Lee et al. 
designed a study using $50 \%$ of MTV SUVmax in 81 LARC patients who were treated with surgery following NACRT. The authors concluded that SUVmax, MTV, and TLG did not predict pCR, without any relationship between MTV and DFS; however, TLG was associated with survival[30]. In another study with rectal cancer patients treated with surgery, although MTV and TLG were found to be associated with DFS in univariate analysis, no significant finding was found in multivariate analysis[31]. Jo et al. reported that MTV and TLG predicted the lymph node positivity in patients with rectal cancer[32]. Similarly, in another study with 166 rectal cancer patients treated with up-front surgery, MTV was shown to predict LN metastasis[33]. In previous studies, pCR has been shown to increase survival rates. Having known the parameters that will predict $\mathrm{PCR}$ before treatment will strengthen the clinician's treatment-decision making[10, 34].

A prospective study of 64 LARC patients treated with NACRT evaluated the relationship between MTV and treatment response and concluded that pre-treatment MTV was associated with treatment response. The cut-off value for MTV was found to be 13.5 , with $84.2 \%$ sensitivity and $47.7 \%$ specificity. In the study, TLG was not associated with treatment response. Although the study had a prospective nature, the treatment modalities of the patients were not heterogeneous, with pretty much missing data [21]. Similarly, in our study, TLG did not affect treatment response, whereas a high MTV prior to treatment decreased the complete response rate and DFS. The fact that the difference in DFS between MTV groups did not reach statistical significance may have been due to small sample size.

Although a homogeneous patient group was selected in our study and presented real-life data, our study had some limitations. It was designed as a retrospective observational study. In addition, the number of cases in our study was relatively low. Besides, it was difficult to promptly apply the suggested optimal cut-off criteria for 18F-FDG-PET/CT parameters in a clinical setting because they were based on a single institutional data set.

In conclusion, we investigated the prognostic effects of baseline volumetric PET/CT parameters (SUVmax, MTV, and TLG) on treatment response and prognosis in locally-advanced rectal cancer (LARC) patients treated with NACRT and showed that TLG and SUVmax did not predict treatment response, while MTV can predict treatment response. We also observed that a greater MTV was associated with reduced DFS. Our study results should be supported by larger studies including greater number of patients.

\section{Declarations}

\section{Compliance with Ethical Standards}

Institutional review board statement: All Necessary procedures for this study were implemented based on the declaration of Helsinki. The ethics committee approval was taken from the Ethics Committee Board of University of Health Sciences Okmeydani Training and Research Hospital (ID:48670771-514.10).

Informed consent statement: The patients were not required to give informed consent for this study because the study utilized the anonymous retrospective data obtained after each patient accepted the 
treatment by a written consent.

Conflict-of-interest statement: All authors declare no conflicts-of-interest.

Funding Source: None.

Author Contributions:Concept - AS, SS, SSK, SC; Design - AS, MMS, MHA, SC; Supervision - SS, SK, MMA, SC; Resources - AS, SSK, SK, MMA; Materials - SK, MHA, MMA, SC; Data Collection and/or Processing - AS, SS, SK, MHA; Analysis and/or Interpretation - SS, SSK, MMK, SC; Literature Search AS, SS, MMA, SC; Writing Manuscript - AS, SS, SSK, SK; Critical Review - SS, SC; Other - AS, SS, SSK, SK.

\section{References}

1. Edge SB, Compton CC (2010) The American Joint Committee on Cancer: the 7th edition of the AJCC cancer staging manual and the future of TNM. Ann Surg Oncol 17:1471-1474

2. Heald RJ (1988) The 'Holy Plane' of rectal surgery. J R Soc Med 81:503-508

3. Li Y, Wang J, Ma X, et al (2016) A Review of Neoadjuvant Chemoradiotherapy for Locally Advanced Rectal Cancer. Int J Biol Sci 12:1022-1031

4. Martin ST, Heneghan HM, Winter DC (2012) Systematic review and meta-analysis of outcomes following pathological complete response to neoadjuvant chemoradiotherapy for rectal cancer. $\mathrm{Br} \mathrm{J}$ Surg 99:918-928

5. Bujko K, Kolodziejczyk M, Nasierowska-Guttmejer A, et al (2010) Tumour regression grading in patients with residual rectal cancer after preoperative chemoradiation. Radiother Oncol 95:298-302

6. Topova L, Hellmich G, Puffer E, et al (2011) Prognostic value of tumor response to neoadjuvant therapy in rectal carcinoma. Dis Colon Rectum 54:401-411

7. Shivnani AT, Small W, Jr., Stryker SJ, et al (2007) Preoperative chemoradiation for rectal cancer: results of multimodality management and analysis of prognostic factors. Am J Surg 193:389-393; discussion 393-384

8. Habr-Gama A, Perez RO, Nadalin W, et al (2004) Operative versus nonoperative treatment for stage 0 distal rectal cancer following chemoradiation therapy: long-term results. Ann Surg 240:711-717; discussion 717-718

9. Maas M, Nelemans PJ, Valentini V, et al (2010) Long-term outcome in patients with a pathological complete response after chemoradiation for rectal cancer: a pooled analysis of individual patient data. Lancet Oncol 11:835-844

10. Sakin A, Sahin S, Sengul Samanci N, et al (2020) The impact of tumor regression grade on long-term survival in locally advanced rectal cancer treated with preoperative chemoradiotherapy. J Oncol Pharm Pract:1078155219900944 
11. Paun BC, Cassie S, MacLean AR, et al (2010) Postoperative complications following surgery for rectal cancer. Ann Surg 251:807-818

12. van der Valk MJM, Hilling DE, Bastiaannet $E$, et al (2018) Long-term outcomes of clinical complete responders after neoadjuvant treatment for rectal cancer in the International Watch \& Wait Database (IWWD): an international multicentre registry study. Lancet 391:2537-2545

13. Appelt AL, Ploen J, Harling H, et al (2015) High-dose chemoradiotherapy and watchful waiting for distal rectal cancer: a prospective observational study. Lancet Oncol 16:919-927

14. Rombouts AJM, Al-Najami I, Abbott NL, et al (2017) Can we Save the rectum by watchful waiting or TransAnal microsurgery following (chemo) Radiotherapy versus Total mesorectal excision for early REctal Cancer (STAR-TREC study)?: protocol for a multicentre, randomised feasibility study. BMJ Open 7:e019474

15. Gallamini A, Zwarthoed C, Borra A (2014) Positron Emission Tomography (PET) in Oncology. Cancers (Basel) 6:1821-1889

16. Boellaard R, Delgado-Bolton R, Oyen WJ, et al (2015) FDG PET/CT: EANM procedure guidelines for tumour imaging: version 2.0. Eur J Nucl Med Mol Imaging 42:328-354

17. Liao S, Penney BC, Wroblewski K, et al (2012) Prognostic value of metabolic tumor burden on 18FFDG PET in nonsurgical patients with non-small cell lung cancer. Eur J Nucl Med Mol Imaging 39:2738

18. Song BI, Kim HW, Won KS, et al (2015) Preoperative Standardized Uptake Value of Metastatic Lymph Nodes Measured by 18F-FDG PET/CT Improves the Prediction of Prognosis in Gastric Cancer. Medicine (Baltimore) 94:e1037

19. Arici S, Karyagar SS, Karyagar S, et al (2020) The predictive role of metabolic tumor volume on no response to neoadjuvant chemotherapy in patients with breast cancer. J Oncol Pharm Pract:1078155219898504

20. Husby JA, Reitan BC, Biermann M, et al (2015) Metabolic Tumor Volume on 18F-FDG PET/CT Improves Preoperative Identification of High-Risk Endometrial Carcinoma Patients. J Nucl Med 56:1191-1198

21. Li QW, Zheng RL, Ling YH, et al (2016) Prediction of tumor response after neoadjuvant chemoradiotherapy in rectal cancer using (18)fluorine-2-deoxy-D-glucose positron emission tomography-computed tomography and serum carcinoembryonic antigen: a prospective study. Abdom Radiol (NY) 41:1448-1455

22. Pellegrino S, Fonti R, Mazziotti E, et al (2019) Total metabolic tumor volume by $18 \mathrm{~F}-F D G$ PET/CT for the prediction of outcome in patients with non-small cell lung cancer. Ann Nucl Med 33:937-944

23. Ryan R, Gibbons D, Hyland JM, et al (2005) Pathological response following long-course neoadjuvant chemoradiotherapy for locally advanced rectal cancer. Histopathology 47:141-146

24. Chen CC, Lee RC, Lin JK, et al (2005) How accurate is magnetic resonance imaging in restaging rectal cancer in patients receiving preoperative combined chemoradiotherapy? Dis Colon Rectum 48:722-728 
25. Rau B, Hunerbein M, Barth C, et al (1999) Accuracy of endorectal ultrasound after preoperative radiochemotherapy in locally advanced rectal cancer. Surg Endosc 13:980-984

26. Calvo FA, Domper M, Matute R, et al (2004) 18F-FDG positron emission tomography staging and restaging in rectal cancer treated with preoperative chemoradiation. Int J Radiat Oncol Biol Phys 58:528-535

27. Mac Manus MP, Hicks RJ, Matthews JP, et al (2003) Positron emission tomography is superior to computed tomography scanning for response-assessment after radical radiotherapy or chemoradiotherapy in patients with non-small-cell lung cancer. J Clin Oncol 21:1285-1292

28. Martoni AA, Zamagni C, Quercia S, et al (2010) Early (18)F-2-fluoro-2-deoxy-d-glucose positron emission tomography may identify a subset of patients with estrogen receptor-positive breast cancer who will not respond optimally to preoperative chemotherapy. Cancer 116:805-813

29. Gauthe M, Richard-Molard M, Fayard J, et al (2017) Prognostic impact of tumour burden assessed by metabolic tumour volume on FDG PET/CT in anal canal cancer. Eur J Nucl Med Mol Imaging 44:6370

30. Lee SJ, Kim JG, Lee SW, et al (2013) Clinical implications of initial FDG-PET/CT in locally advanced rectal cancer treated with neoadjuvant chemoradiotherapy. Cancer Chemother Pharmacol 71:12011207

31. Jo HJ, Kim SJ, Lee HY, et al (2014) Prediction of survival and cancer recurrence using metabolic volumetric parameters measured by 18F-FDG PET/CT in patients with surgically resected rectal cancer. Clin Nucl Med 39:493-497

32. Jo HJ, Kim SJ, Kim IJ, et al (2014) Predictive value of volumetric parameters measured by F-18 FDG $\mathrm{PET} / \mathrm{CT}$ for lymph node status in patients with surgically resected rectal cancer. Ann Nucl Med 28:196-202

33. Kim SH, Song BI, Kim BW, et al (2019) Predictive Value of [(18)F]FDG PET/CT for Lymph Node Metastasis in Rectal Cancer. Sci Rep 9:4979

34. Beddy D, Hyland JM, Winter DC, et al (2008) A simplified tumor regression grade correlates with survival in locally advanced rectal carcinoma treated with neoadjuvant chemoradiotherapy. Ann Surg Oncol 15:3471-3477

\section{Tables}

Tables 1 Patient characteristic 


\begin{tabular}{|c|c|c|c|c|c|c|c|c|}
\hline \multirow[t]{2}{*}{ Characteristics } & & \multicolumn{2}{|c|}{$\begin{array}{l}\text { All } \\
\text { Patients } \\
(n=51)\end{array}$} & \multicolumn{2}{|c|}{$\begin{array}{l}\text { Group I } \\
(n=14)\end{array}$} & \multicolumn{2}{|c|}{$\begin{array}{l}\text { Group II } \\
(n=37)\end{array}$} & \multirow[t]{2}{*}{$\mathbf{p}$} \\
\hline & & $\mathbf{n}$ & $\%$ & $\mathbf{n}$ & $\%$ & $\mathrm{n}$ & $\%$ & \\
\hline \multirow[t]{2}{*}{ Gender } & Male & 34 & 66.7 & 9 & 64.3 & 25 & 67.6 & 0.997 \\
\hline & Female & 17 & 33.3 & 5 & 35.7 & 12 & 32.4 & \\
\hline Age & median (min-max) & \multicolumn{2}{|c|}{$55(37-78)$} & \multicolumn{2}{|c|}{$\begin{array}{l}57.5(37- \\
78)\end{array}$} & \multicolumn{2}{|c|}{$54(39-74)$} & 0.175 \\
\hline \multirow[t]{2}{*}{ Smoking status } & No & 21 & 41.2 & 8 & 57.1 & 13 & 35.1 & 0.154 \\
\hline & Yes & 30 & 58.8 & 6 & 42.9 & 24 & 64.9 & \\
\hline \multirow{2}{*}{$\begin{array}{l}\text { Alcohol } \\
\text { consumption }\end{array}$} & No & 48 & 94.1 & 14 & 100 & 34 & 91.9 & 0.552 \\
\hline & Yes & 3 & 5.9 & 0 & 0 & 3 & 8.1 & \\
\hline \multirow[t]{2}{*}{ CIHD } & No & 45 & 88.2 & 11 & 78.6 & 34 & 91.9 & 0.327 \\
\hline & Yes & 6 & 11.8 & 3 & 21.4 & 3 & 8.1 & \\
\hline \multirow[t]{2}{*}{ DM } & No & 41 & 80.4 & 13 & 92.9 & 28 & 75.7 & 0.250 \\
\hline & Yes & 10 & 19.6 & 1 & 7.1 & 9 & 24.3 & \\
\hline \multirow[t]{2}{*}{$\mathrm{HT}$} & No & 39 & 76.5 & 9 & 64.3 & 30 & 81.1 & 0.272 \\
\hline & Yes & 12 & 23.5 & 5 & 35.7 & 7 & 18.9 & \\
\hline \multirow[t]{2}{*}{ ECOG PS } & 0 & 49 & 96.1 & 13 & 92.9 & 36 & 97.3 & 0.478 \\
\hline & 1 & 2 & 3.9 & 1 & 7.1 & 1 & 2.7 & \\
\hline \multirow[t]{2}{*}{ Pathology } & Adenocarcinoma & 46 & 90.2 & 14 & 100 & 32 & 86.5 & 0.305 \\
\hline & $\begin{array}{l}\text { Mucinous } \\
\text { adenocarcinoma }\end{array}$ & 5 & 9.8 & 0 & 0 & 5 & 13.5 & \\
\hline \multirow[t]{3}{*}{ Grade } & 1 & 5 & 9.8 & 3 & 21.4 & 2 & 5.4 & 0.219 \\
\hline & 2 & 42 & 82.4 & 10 & 71.4 & 32 & 86.5 & \\
\hline & 3 & 4 & 7.8 & 1 & 7.1 & 3 & 8.1 & \\
\hline \multirow[t]{3}{*}{ урTNM } & $0-1$ & 16 & 31.4 & 10 & 71.4 & 6 & 16.2 & 0.001 \\
\hline & II & 20 & 39.2 & 3 & 21.4 & 17 & 45.9 & \\
\hline & III & 15 & 29.4 & 1 & 7.1 & 14 & 37.8 & \\
\hline \multirow[t]{2}{*}{ Perineural invasion } & Absent & 34 & 66.7 & 12 & 85.7 & 22 & 59.5 & 0.102 \\
\hline & Present & 17 & 33.3 & 2 & 14.3 & 15 & 40.5 & \\
\hline
\end{tabular}




\begin{tabular}{|lllllllll|}
\hline $\begin{array}{l}\text { Lenfovascular } \\
\text { invasion }\end{array}$ & Absent & 41 & 80.4 & 13 & 92.9 & 28 & 75.7 & 0.250 \\
\cline { 2 - 9 } & Present & 10 & 19.6 & 1 & 7.1 & 9 & 24.3 & \\
\hline Margin & Negative & 48 & 94.1 & 14 & 100 & 34 & 91.9 & 0.552 \\
\cline { 2 - 9 } & Positive & 3 & 5.9 & 0 & 0 & 3 & 8.1 & \\
\hline Adjuvant therapy & No & 10 & 19.6 & 3 & 21.4 & 7 & 18.9 & 1.000 \\
\cline { 2 - 9 } & Yes & 41 & 80.4 & 11 & 78.6 & 30 & 81.1 & \\
\hline Recurrence & FOLFOX-XELOX & 16 & 31.4 & 2 & 18.2 & 14 & 46.7 & 0.323 \\
\cline { 2 - 9 } & FUFA-Capecitabine & 25 & 58.6 & 9 & 81.8 & 16 & 53.3 & \\
\hline Final status & No & 40 & 78.4 & 12 & 85.7 & 28 & 75.7 & 0.705 \\
\cline { 2 - 9 } & Yes & 11 & 21.6 & 2 & 14.3 & 9 & 24.3 & \\
\hline Follow up (month) & median (min-max) & $11(5-30)$ & $11(7-30)$ & $13(5-27)$ & 0.478 \\
\hline
\end{tabular}

Abbreviations: CIHD, Chronic Ischemic Heart Disease; DM, Diabetes Mellitus; ECOG PS, Eastern Cooperative Oncology Group Performance Status; HT, Hypertension.

Table 2. Comparison of MTV, TLG, and SUV according to TRG groups.

\begin{tabular}{|lllll|}
\hline Characteristics & & Group I & Group II & p \\
\hline Primary lesion MTV & Median (Mean) & $10.4 \pm 5.9(9.7)$ & $19.5 \pm 15.1(16)$ & 0.006 \\
& Min-max & $2.4-20.5$ & $6-83$ & \\
\hline Primary lesion TLG & Median (Mean) & $95.2 \pm 63.5(84.2)$ & $181.1 \pm 193.3(128)$ & 0.033 \\
& Min-max & $4.5-243.8$ & $34-1184$ & \\
\hline Primary lesion SUVmax & Median (Mean) & $9.5 \pm 5.0(9.4)$ & $8.8 \pm 3.1(8)$ & 0.673 \\
& Min-max & $1.9-19.2$ & $4-18$ & \\
\hline
\end{tabular}

Abbreviations: MTV, Metabolic tumor volume; SUVmax, Maximum standard uptake value; TLG, Tumor lesion glycolysis.

Table 3. Multivariate analysis for TRG 


\begin{tabular}{|lllll|}
\hline Characteristics & & OR & $\% 95 \mathrm{Cl}$ & $\mathbf{p}$ \\
\hline Smoking & Yes vs No & 0.255 & $0.055-1.184$ & 0.081 \\
\hline DM & Yes vs No & 0.113 & $0.010-1.264$ & 0.077 \\
\hline Lenfovascular invasion & Yes vs No & 0.138 & $0.011-1.672$ & 0.120 \\
\hline MTV & $<12$ vs $>12$ & 5.002 & $1.170-21.383$ & $\mathbf{0 . 0 3 0}$ \\
\hline
\end{tabular}

Abbreviations: DM, Diabetes Mellitus; MTV, Metabolic tumor volume; OR, Odds ratio; $\mathrm{Cl}$, Confidence interval.

Figures

\section{Image not available with this version}

Figure 1

In the ROC curve plotted for MTV and TLG, the areas under the curve $(95 \% \mathrm{Cl})$ were $0.749(0.593-0.905)$ and 0.695 (0.536-0.854), respectively. The cut-off value for MTV was 12 , with $70 \%$ sensitivity and $65 \%$ specificity. The cut-off value for TLG was 92.4 , with $75 \%$ sensitivity and $58 \%$ specificity.

\section{Image not available with this version}

Figure 2 
Disease-free survival according to TLG groups. 